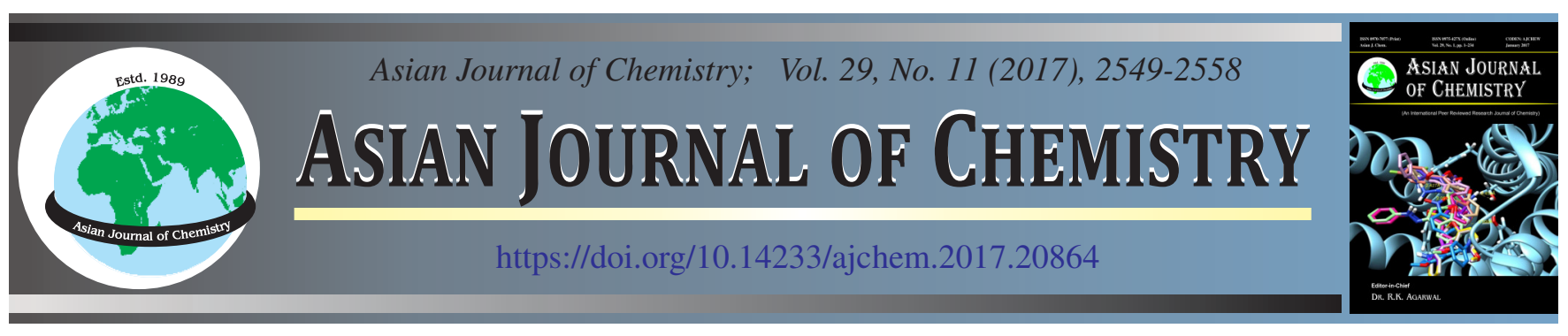

\title{
Zirconium-Treated Fine Red Mud Impregnated in Zn-Alginate Beads as Adsorbent in Removal of Phosphate from Water
}

\author{
G.V. Krishna Mohan, A. Naga Babu, K. Kalpana and K. Ravindhranath*
}

Department of Chemistry, K.L. University, Green Fields, Vaddeswaram-522 502, India

*Corresponding author: E-mail: ravindhranath.kunta@gmail.com

\begin{abstract}
Zirconium-treated fine red mud impregnated in Zn-alginate beads (ZRMAB) are investigated for their adsorption nature towards phosphate from water by varying various physico-chemical parameters such as $\mathrm{pH}$, time of equilibration, sorbent dosage, initial concentration of phosphate, presence of co-anions and temperature. The extraction conditions are optimized for the maximum removal of phosphate and the sorption ability is found to be $13.64 \mathrm{mg} / \mathrm{g}$ of the adsorbent. Substantial amounts of phosphate are removed even after ten times of regeneration of the adsorbent. Repetitive use of the same adsorbent completely removes phosphate from water. Surface morphological studies using XRD, FTIR, FESEM and EDX confirm the phosphate is onto the surface of the adsorbent. Adsorption isotherms and kinetic of sorption are analyzed and thermodynamic studies are made. The procedure developed is successfully applied to the removal of phosphate from polluted ground water samples
\end{abstract}

Keywords: Zirconium treated red mud, Zinc-alginate beads, Phosphate.

\section{INTRODUCTION}

The un-conventional methods in treating the polluted waters are proving to be effective, simple and economical. Our research group successfully developed methods for the removal of various pollutants such as $\mathrm{Cr}$ (VI) [1-4], $\mathrm{Zn}$ (II) [5], $\mathrm{Al}(\mathrm{III})$ [6-9], $\mathrm{F}^{-}$[10-15], $\mathrm{NO}_{2}^{-}$[16,17], $\mathrm{NH}_{3}$ [18-20], $\mathrm{PO}_{4}{ }^{3-}$ $[21,22]$ and dyes [23-25] based on the adsorbents derived from various plants.

In continuation of our efforts in these lines of research, we herewith report an adsorbent developed with treated red mud and its absorptivity towards phosphate ions from waste waters.

The literature survey indicates that the red mud, a waste product from aluminium industries, is explored for its sorption nature for the removal of various pollutants [26-34]. In our primary investigations, red mud obtained from aluminium industries is activated with various reagents such as different acids, bases, oxidizing agents $\left(\mathrm{H}_{2} \mathrm{O}_{2}\right)$, reducing agents (hydrazine sulphate) and by treating with various salts (zirconium oxy chloride). It is observed that zirconium oxychloride treated red mud shows strong affinity towards phosphate ions. The treated red mud is immobilized in the zinc-alginate beads prepared by using zinc sulphate for cross linking. Thus obtained zirconium treated red mud entrapped in zinc-alginate beads (ZRMAB) is studied for its adsorption nature towards phosphate ions from waste waters. The present work is a detailed account of optimizing the sorption nature of the adsorbent towards the maximum removal of phosphate from water and applications.

\section{EXPERIMENTAL}

All the chemicals used in this work are analytical grade and are purchased from Merck \& Co. and SD Fine Chemicals Pvt Ltd. The red mud was obtained from Vedanta Aluminium Ltd, Utkal Alumina, Lanjigarh refinery, Rayagada, India and analyzed by standard procedures. The obtained chemical composition is presented in Table- 1 .

Treatment: The collected raw red mud sample was repeatedly washed with distilled water till the washings were neutral to

\begin{tabular}{lc}
\multicolumn{2}{c}{ TABLE-1 } \\
\multicolumn{1}{c}{ CHEMICAL PROPERTIES OF RED MUD } \\
\hline \multicolumn{1}{c}{ Parameter } & Result (\%) \\
\hline Alumina as $\mathrm{Al}_{2} \mathrm{O}_{3}$ & 15.47 \\
Iron as $\mathrm{Fe}_{2} \mathrm{O}_{3}$ & 58.78 \\
Silica as $\mathrm{SiO}_{2}$ & 6.58 \\
Titanium as $\mathrm{TiO}_{2}$ & 4.39 \\
Soda as $\mathrm{Na}_{2} \mathrm{O}$ & 3.63 \\
Calcium as $\mathrm{CaO}$ & 1.49 \\
Phosphorus as $\mathrm{P}_{2} \mathrm{O}_{5}$ & 0.159 \\
Vanadium as $\mathrm{V}_{2} \mathrm{O}_{5}$ & 0.110 \\
Loss on ignition $(\mathrm{LOI})\left(105-1000{ }^{\circ} \mathrm{C}\right)$ & 7.22 \\
\hline
\end{tabular}


$\mathrm{pH}$ and then the red mud was dried for $2 \mathrm{~h}$ at $105^{\circ} \mathrm{C}$ in a oven. Then the red mud was grinded to fine powder and sieved to $75 \mu$. Then $1 \%$ zirconium oxychloride solution was added to the fine red mud sample in the ratio of 1:2 (w/w) and the resulting solution was boiled for $2 \mathrm{~h}$ at $110^{\circ} \mathrm{C}$. The sample was filtered, washed with distilled water repeatedly and dried at $105^{\circ} \mathrm{C}$ for $2 \mathrm{~h}$ and then stored in air-tight coloured bottle for further work.

Impregnating Zinc-alginate beads with the treated red mud: $3.0 \mathrm{~g}$ of sodium alginate powder was slowly added to a $100 \mathrm{~mL}$ of double distilled water taken into a $250 \mathrm{~mL}$ beaker by continuous stirring and maintaining $1000 \mathrm{rpm}$ at $90{ }^{\circ} \mathrm{C}$ until the solution is clear and homogenous. Then to this solution, $1 \mathrm{~g}$ of zirconium treated red mud was slowly added by stirring at $90^{\circ} \mathrm{C}$ and the resulting mixture was cooled to room temperature. This solution was then added in dropwise using burette to 100 $\mathrm{mL}$ of $2 \%$ zinc sulphate solution which was kept at $-2{ }^{\circ} \mathrm{C}$. (Fig. 1). Uniform-sized red mud doped zinc alginate beads were formed. These beads were filtered, washed with double distilled water to remove the additional zinc sulphate on beads and dried at $70{ }^{\circ} \mathrm{C}$ and stored in coloured bottle.

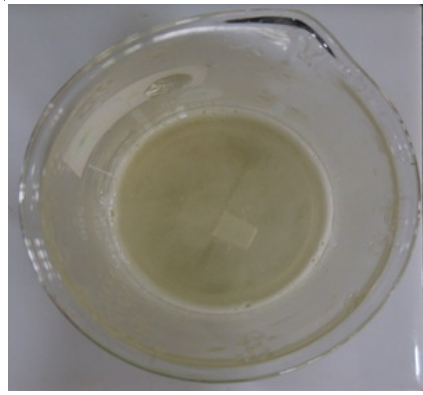

$3.0 \%$ Sodium-alginate solution

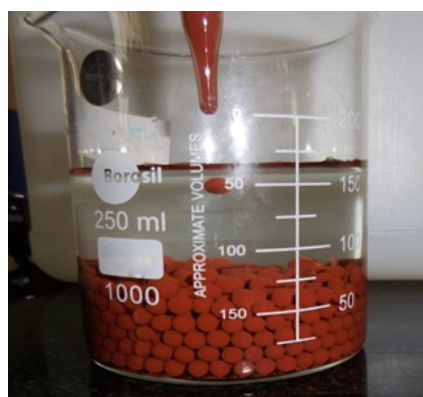

Formation of $\mathrm{Zn}$-alginate beads doped with treated red mud

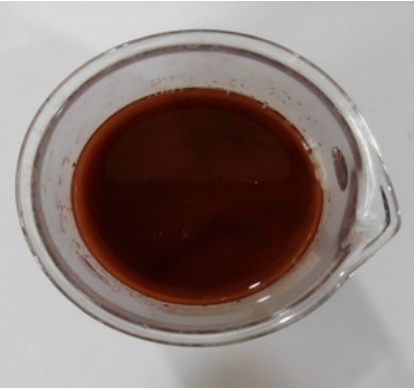

Treated red mud and sodium alginate mixture

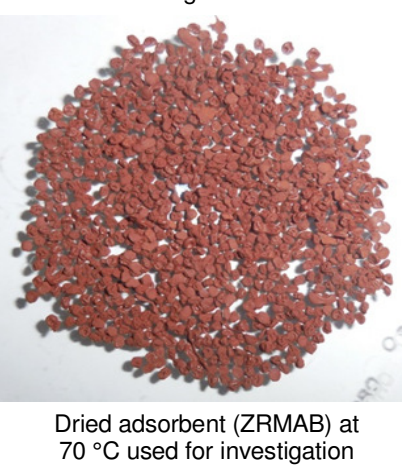

Fig. 1. Zr-treated red mud $\mathrm{Zn}$-alginate beads

Surface characterization: FESEM images of the adsorbent (ZRMAB) were taken at 500 to $15,000 \mathrm{X}$ magnifications at accelerating voltage of $15000 \mathrm{~V}$ by using the instrument HITACHI S-3700N SEM, manufactured by HITACHI high-technologies Ltd., India. FTIR spectra of the adsorbent (ZRMAB) before and after adsorption of phosphate was recorded by using SHIMADZU (8400S) FTIR spectrophotometer in range 4000 to $500 \mathrm{~cm}^{-1}$ at room temperature. $\mathrm{KBr}$ pellet method was adopted at optical resolution of $4 \mathrm{~cm}^{-1}$.

XRD spectra was recorded for the adsorbent (ZRMAB) before and after adsorption of phosphate by using SHIMADZU (XRD 7000) with continuous scan mode of range 10.000 to 80.000, scan speed 2.000 (deg/min), X-Ray $\mathrm{Cu} \mathrm{K \alpha}$ radiation at $40 \mathrm{kV}$ voltage and drive axis between $\theta-2 \theta$. By using HITACHI (S-3700N) EDX detector, EDX spectrum of the adsorbent before and after adsorption of phosphate was recorded.

The $\mathrm{pH}_{\mathrm{ZPC}}$ of adsorbent (ZRMAB) was determined by using HANNA pH meter, model HI2211-02 by adopting the $\mathrm{pH}$ equilibrium method $[35,36]$.

Method: Batch methods of adsorption experiments were adopted using as reported method [37-39]. $100 \mathrm{~mL}$ phosphate solutions of concentration $50 \mathrm{mg} / \mathrm{L}$, were taken into $250 \mathrm{~mL}$ conical flasks and to them different quantities of adsorbent ( 0.5 to $5 \mathrm{~g}$ ) were added. Then, the $\mathrm{pHs}$ were adjusted to 2 to 12 by using $0.1 \mathrm{M} \mathrm{HCl}$ and $0.1 \mathrm{M} \mathrm{NaOH}$ solutions and the conical flasks were shaken using the orbital shaker at $250 \mathrm{rpm}$ for 180 min at room temperature $\left(30^{\circ} \mathrm{C} \pm 1{ }^{\circ} \mathrm{C}\right)$. After the completion of the required time intervals, the conical flasks were removed from the orbital shaker and filtered by using Whatman No.1 filter paper. The phosphate in the solution was analyzed spectrophotometrically by "Molybdenum Blue" method [40] using the instrument UV-159 model spectrophotometer (ELICO).

The adsorbed amount of phosphate and the percentage removal was calculated by using the following eqns. 1 and 2 :

$$
\begin{gathered}
\text { Adsorbed amount }\left(\mathrm{q}_{\mathrm{e}}\right)=\frac{\left(\mathrm{C}_{\mathrm{i}}-\mathrm{C}_{\mathrm{e}}\right)}{\mathrm{m}} \mathrm{V} \\
\operatorname{Removal}(\%)=\frac{\left(\mathrm{C}_{\mathrm{i}}-\mathrm{C}_{\mathrm{e}}\right)}{\mathrm{C}_{\mathrm{i}}} \times 100
\end{gathered}
$$

where $C_{i}=$ initial concentration of the phosphate ion solution $(\mathrm{mg} / \mathrm{L}), \mathrm{C}_{\mathrm{e}}=$ equilibrium concentration of the phosphate solution $(\mathrm{mg} / \mathrm{L}), \mathrm{V}=$ volume of the phosphate ion solution in litres and $\mathrm{m}=$ mass of the adsorbent in grams.

In finding the effect of various physico-chemical parameters such as adsorbent dosage, $\mathrm{pH}$, initial concentration of phosphate ions, interference of co-ions and temperature on the $\%$ removal of phosphate by the zirconium treated red mudzinc alginate beads as an adsorbent, the above experimental procedure was adopted.

\section{RESULTS AND DISCUSSION}

\section{Characterization of ZRMAB}

SEM: FESEM provides surface morphology of adsorbent (ZRMAB) before and after phosphate adsorption at microscale. The FESEM images at different magnifications were presented in Fig. 2. Before adsorption, the images show many cavities, micro and macro pores and corners. Moreover, some crystalline aggregates belongs to mineral phases such as hematite, goethite, gibbsite are also appeared. But the images show emphatic change after adsorption of the phosphate as seen from the decrease in pores and edges indicating that the phosphate is onto the surface of the adsorbent. The same is further confirmed from the electronic images (Fig. 3) taken before and after adsorption.

FTIR: The FTIR spectrum of before and after adsorption of the phosphate onto the adsorbent (ZRMAB) were presented in the Fig. 4.

The broad spectral bands with peak at $3441 \mathrm{~cm}^{-1}$ (before adsorption) and $3450 \mathrm{~cm}^{-1}$ (after adsorption) pertain to $\mathrm{O}-\mathrm{H}$ stretching vibrations of coordinate water molecules. The peak 


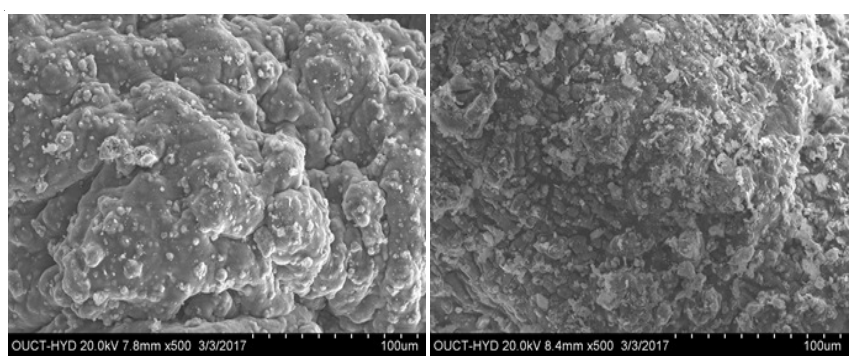

SEM images of adsorbent before and after phosphate adsorption at $500 \mathrm{X}$ resolution

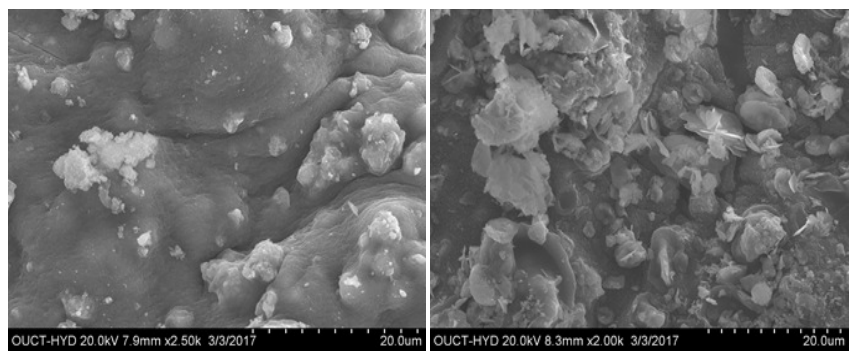

SEM images of adsorbent before and after phosphate adsorption at 1000X resolution Fig. 2. SEM images of adsorbent (ZRMAB)
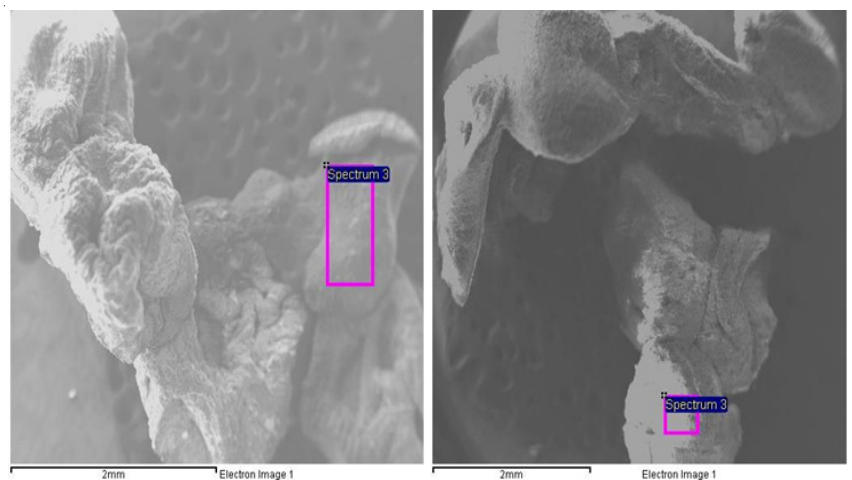

Fig. 3. Electronic images of adsorbent (ZRMAB) before and after phosphate adsorption
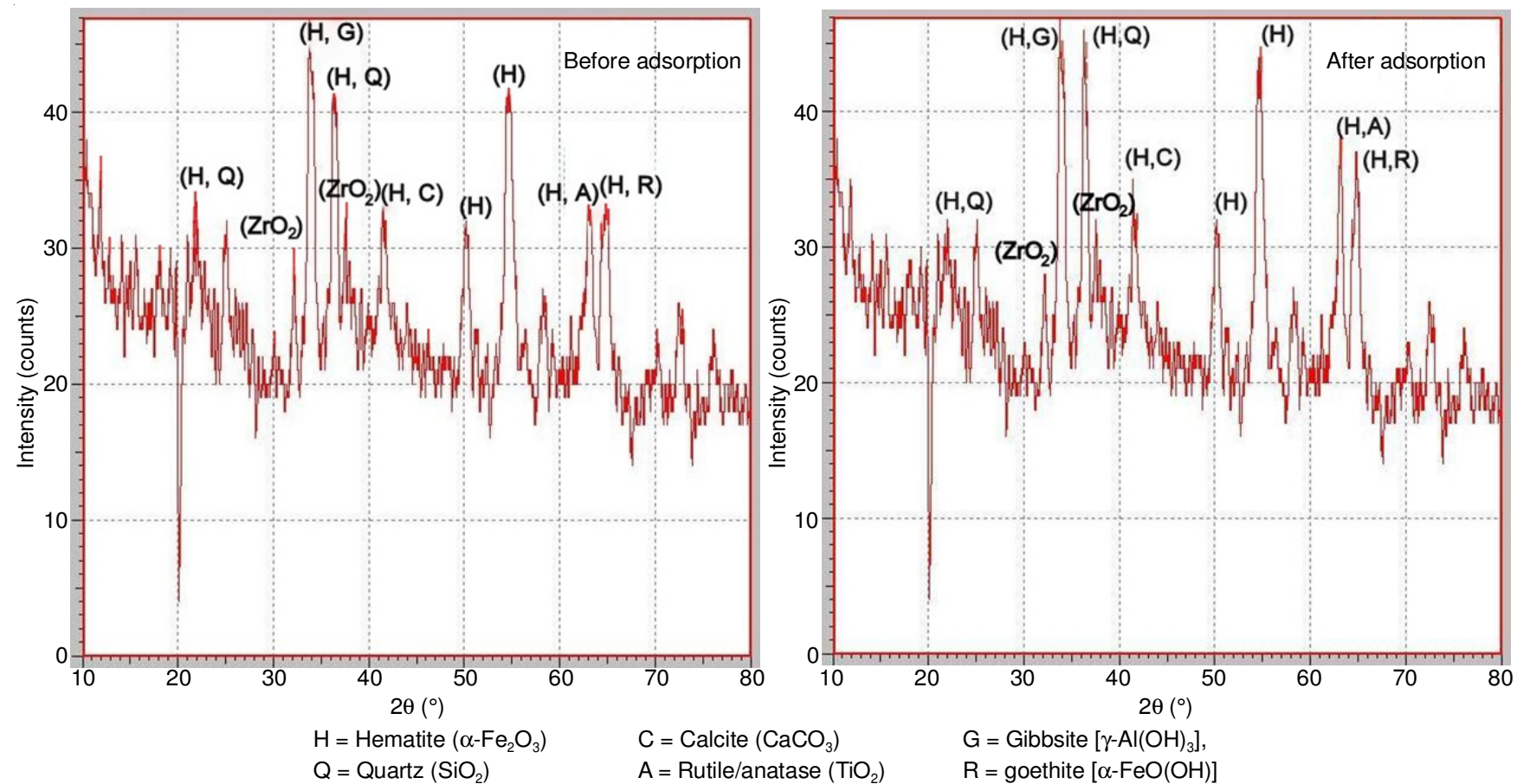

Fig. 5. XRD spectra of adsorbent (ZRMAB)) before and after adsorption of phosphate

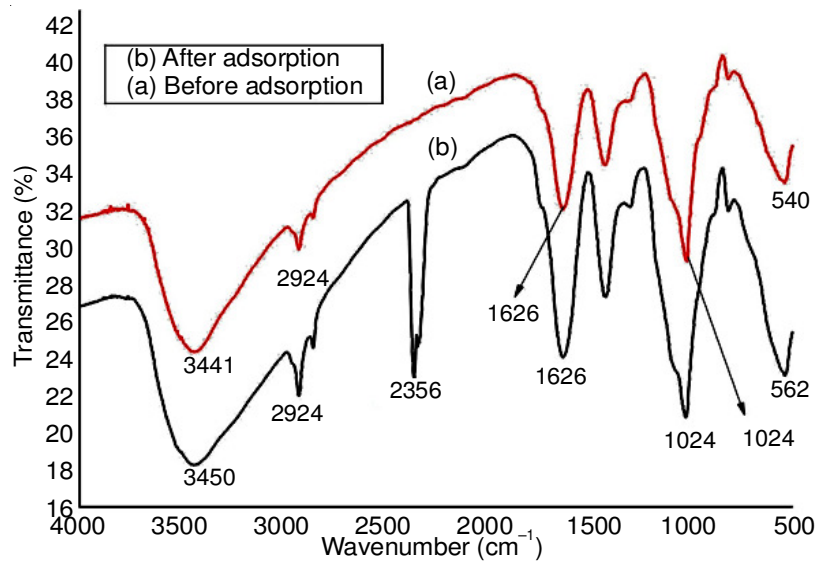

Fig. 4. FTIR spectra of adsorbent (ZRMAB)

at $1626 \mathrm{~cm}^{-1}$ in both before and after adsorption spectrum is assigned to hydroxyl $(\mathrm{OH})$ bending vibrations. The drastic contrast between before and after adsorption peaks is found in the appearance of a strong peak at $2356 \mathrm{~cm}^{-1}$ pertains to $\mathrm{OH}$ stretchings in $\mathrm{O}=\mathrm{P}-\mathrm{OH}$ functional group in the spectrum taken after adsorption of phosphate [41]. This is clear evidence that the phosphate is on to the surface of the adsorbent.

XRD: The crystalline phases of adsorbent (ZRMAB) before and after adsorption of phosphate were studied by XRD spectrum. The observed spectral phases are presented in the Fig. 5. As per the data in JCPDS, the spectrum clearly show the existence of the phases such as, hematite $\left(\alpha-\mathrm{Fe}_{2} \mathrm{O}_{3}\right)$, goethite $(\alpha-\mathrm{FeO}(\mathrm{OH}))$, calcite $\left(\mathrm{CaCO}_{3}\right)$, gibbsite $\left(\gamma-\mathrm{Al}(\mathrm{OH})_{3}\right)$, rutile/anatase $\left(\mathrm{TiO}_{2}\right)$ and quartz $\left(\mathrm{SiO}_{2}\right)$ and further more zirconium oxide peaks also appeared at 33.51 and 38.66 as the adsorbent is treated with zirconium salts. The increase in intensity of hematite $(\alpha-$ $\left.\mathrm{Fe}_{2} \mathrm{O}_{3}\right)$, goethite $(\alpha-\mathrm{FeO}(\mathrm{OH}))$ and gibbsite $\left(\gamma-\mathrm{Al}(\mathrm{OH})_{3}\right)$ and zirconium oxide peaks in the after adsorption spectrum indicate that phosphate was onto the surface of adsorbent (ZRMAB). 
EDX spectrum: EDX spectrum of adsorbent (ZRMAB) before and after adsorption of phosphate were shown in Fig. 6. A clear peak of phosphorus was noticed in the after adsorption spectrum when compared with the before adsorption spectrum. This is the best evidence that phosphate is successfully adsorbed onto the adsorbent surface (ZRMAB). Moreover, the existence of spectral peaks pertain to zirconium at 2.3 in both the spectrums reflect that the zirconium is well doped in the adsorbent beads.
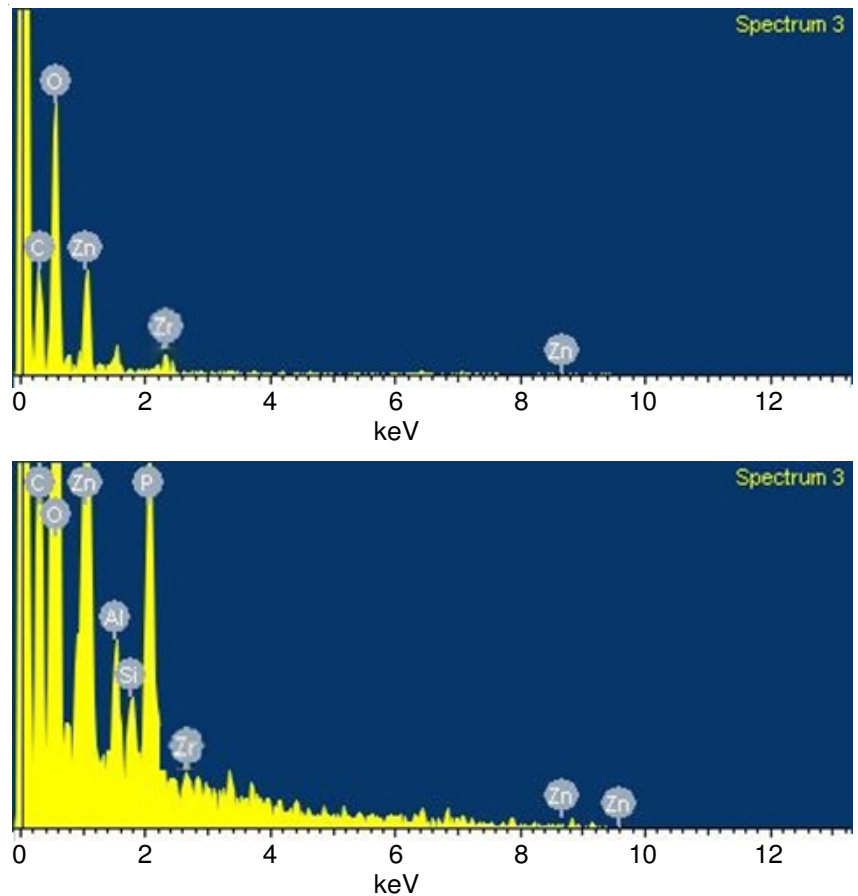

Fig. 6. EDX spectra of adsorbent (ZRMAB) before and after adsorption of phosphate

Impact of different physico-chemical factors on phosphate removal: Under various physico-chemical parameters such as $\mathrm{pH}$, contact time, sorbent dosage, initial concentration of phosphate solution, temperature and interfering anions, the percentage removal of phosphate was studied using ZRMAB as an adsorbent. The obtained results were presented hereunder comprehensively.

pH: It is known that pH plays an important role in whole adsorption process in view of the fact that the $\mathrm{pH}$ influences the dissociation, or association of the functional groups present on the adsorbent at solution-adsorbent interface. Hence, the optimum $\mathrm{pH}$ for the successful removal of phosphate has been investigated by varying the $\mathrm{pH}$ conditions from 2 to 12 while keeping the other conditions of extraction at optimum levels namely agitation time: $120 \mathrm{~min}$, rpm: 250 , sorbent dosage: $1 \mathrm{~g} /$ $100 \mathrm{~mL}$, initial concentration: $50 \mathrm{mg} / \mathrm{L}$ and temperature $30 \pm$ $1{ }^{\circ} \mathrm{C}$, the observations are presented in Fig. 7(b)

It is inferred that the maximum $90.0 \%$ of phosphate is removed at $\mathrm{pH}$ : 8 . Below and above of this optimum $\mathrm{pH}$, the percentage removal of phosphate is decreased. To understand the nature of adsorption, $\mathrm{pHzpc}$, has been investigated and a graph is drawn between initial $\mathrm{pH}$ and final $\mathrm{pH}$ as depicted in Fig. 7(a). The curves cross at 8.1 and it is called as pHzpc. Its significance is that below this value, the adsorbent surface

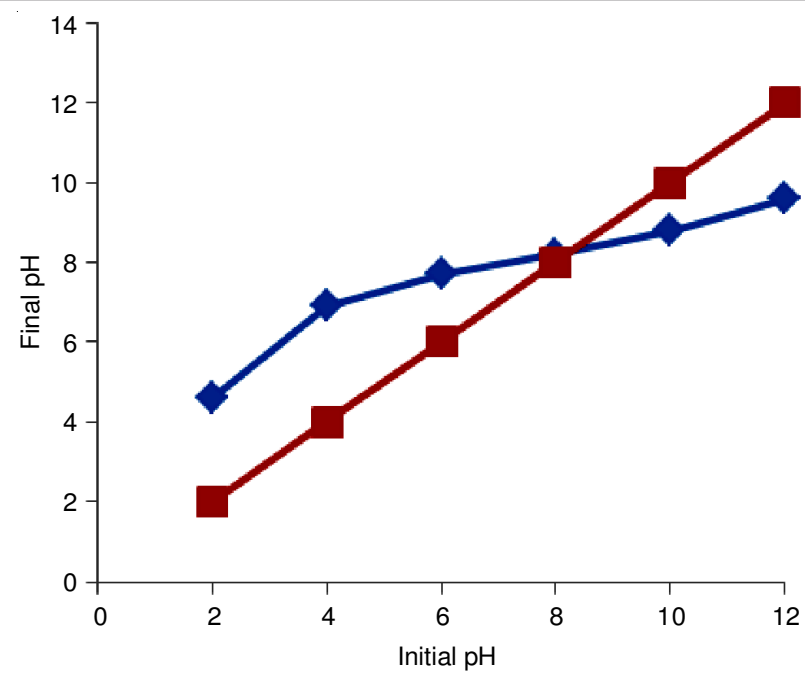

Fig. 7(a). pHZPC of adsorbent (ZRMAB)

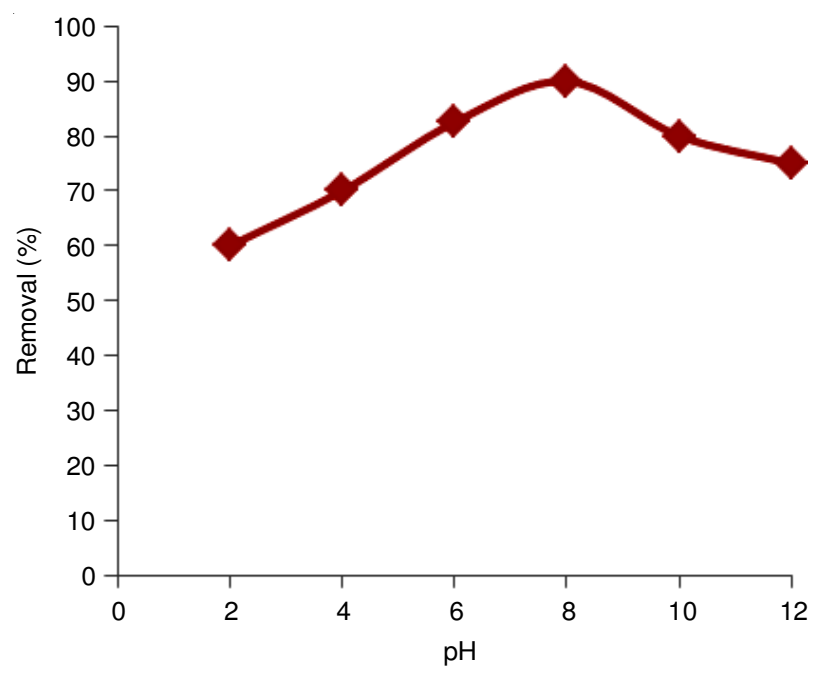

Fig. 7(b). Effect of $\mathrm{pH}$ on the adsorption of Phophate

acquires positive charge due to the protonation of surface functional groups and above this value, the surface is endowed with negative charge due to the dissociation of the functional groups. As the species of phosphate are negatively charged at $\mathrm{pH}: 8$, their affinity towards the negatively charged surface at higher $\mathrm{pH}$ value is low and hence low $\%$ of removal. However, with the decrease of $\mathrm{pH}$, the dissociation of surface functional groups is not favoured and it results in the increase of phosphate removal. However at very low $\mathrm{pH}$ values, the predominant phosphate species is neutral and hence \% removal decreases. For good adsorption, the phosphate species must possesses negative charge and the adsorbent surface must have positive charge. These conditions seems to be acquired at $\mathrm{pH}: 8$.

Effect of contact time: The \% removal of phosphate at different time intervals while keeping other conditions of extraction constant at optimum levels has been studied and the results are present in Fig. 7(c). As the agitation time is increased from 0 to $150 \mathrm{~min}$, the removal of phosphate is increased from 55.0 to $90.0 \%$. Initially the adsorption is more and infact $55.0 \%$ removal is found even within 15 min of agitation but the removal is slowed down with time and the maximum of $90.0 \%$ is attained only at $120 \mathrm{~min}$ of agitation and it remains almost constant with further increase agitation 


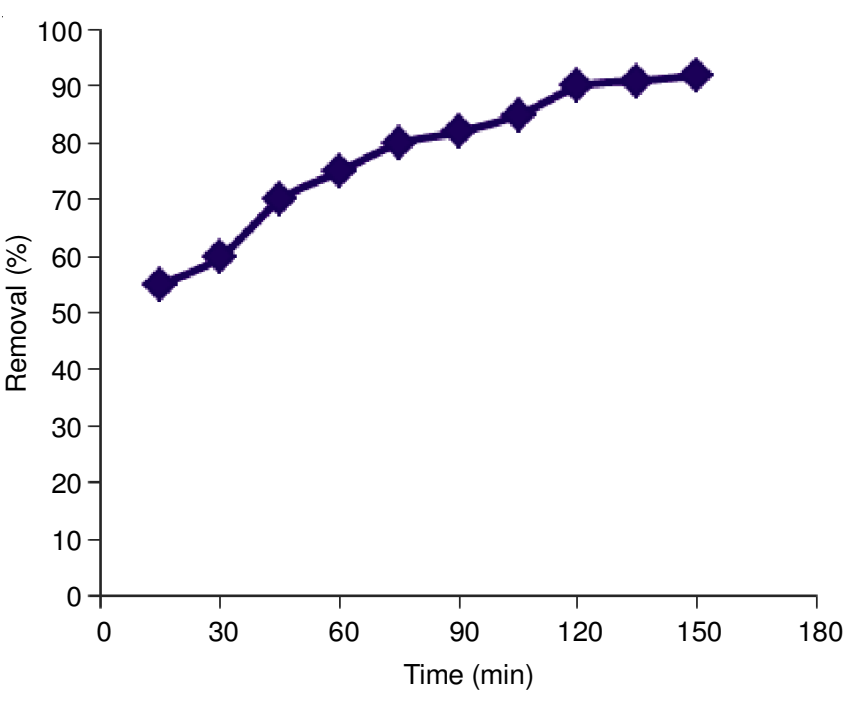

Fig. 7(c). Effect of time on the adsroption of phosphate

of time up to $150 \mathrm{~min}$. This indicates the reaching of equilibrium state between the adsorbent and adsorbate (phosphate) after 120 min of agitation. The rapid adsorption initially is due to the more availability of vacant sites on the adsorbent for causing the adsorption of phosphate ions but with time, the vacant sites are used up and their availability less for phosphate ions and hence the adsorption is slow down.

Effect of adsorbent dosage: The optimum dosage of adsorbent concentration is assessed by investigating the \% removal by varying the dosage from $0.25 \mathrm{~g}$ to $1.5 \mathrm{~g}$ of beads $/ 100 \mathrm{~mL}$ while maintaining other conditions of extraction at optimum levels. The obtained results are presented in Fig. 7(d).

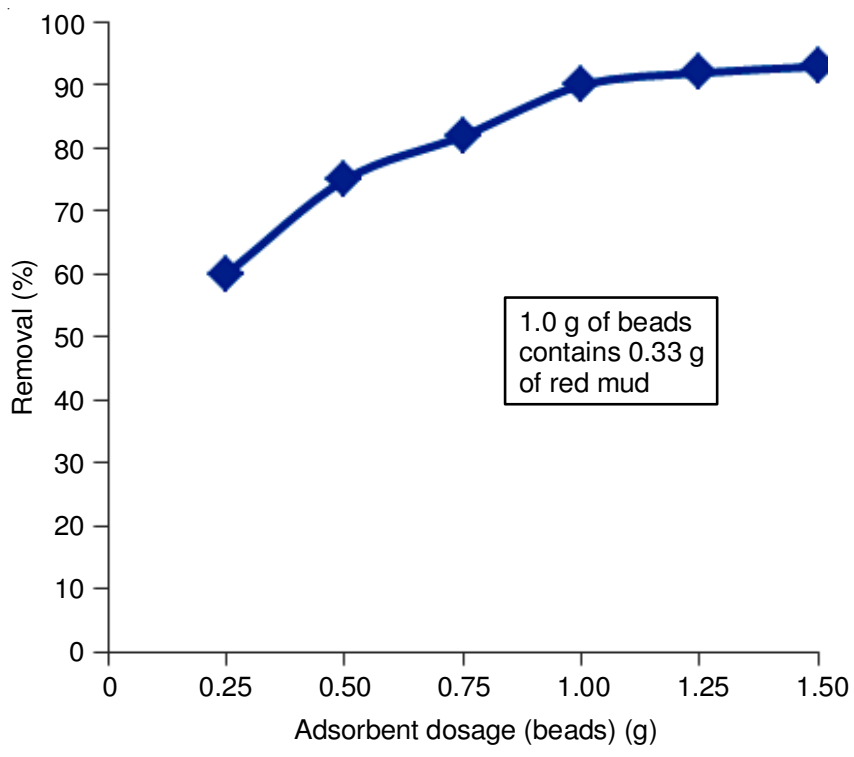

Fig. 7(d). Effect of sorbent dosage on the adsorption

With increase in the adsorbent dosage, the percentage removal of phosphate also increases: $60.0 \%$ with $0.25 \mathrm{~g} ; 75.0$ $\%$ with $0.50 \mathrm{~g}, 82.0 \%$ with $0.75 \mathrm{~g}, 90.0 \%$ with $1.0 \mathrm{~g}, 92.0 \%$ with $1.25 \mathrm{~g}$ and $93.0 \%$ with $1.5 \mathrm{~g}$. As is noted that \% removal almost remains constant even when the adsorbent dosage is increased from 1.0 to $1.5 \mathrm{~g} / 100 \mathrm{~mL}$ indicating the reaching of equilibrium. The optimum dosage is $1.0 \mathrm{~g} / 100 \mathrm{~mL}$ (in terms of beads).
Initial concentration: The effect of initial concentration of phosphate in the simulated solution on the \% removal is studied by varying the initial concentration from 20 to $90 \mathrm{mg} /$ L while maintaining other conditions of extraction at optimum levels. The results obtained are presented in the Fig. 7(e). It can be noted that as the concentration of phosphate ions increases from $20 \mathrm{mg} / \mathrm{L}$ to $90 \mathrm{mg} / \mathrm{L}$, \% removal decreases from 95.0 to $67.0 \%$.

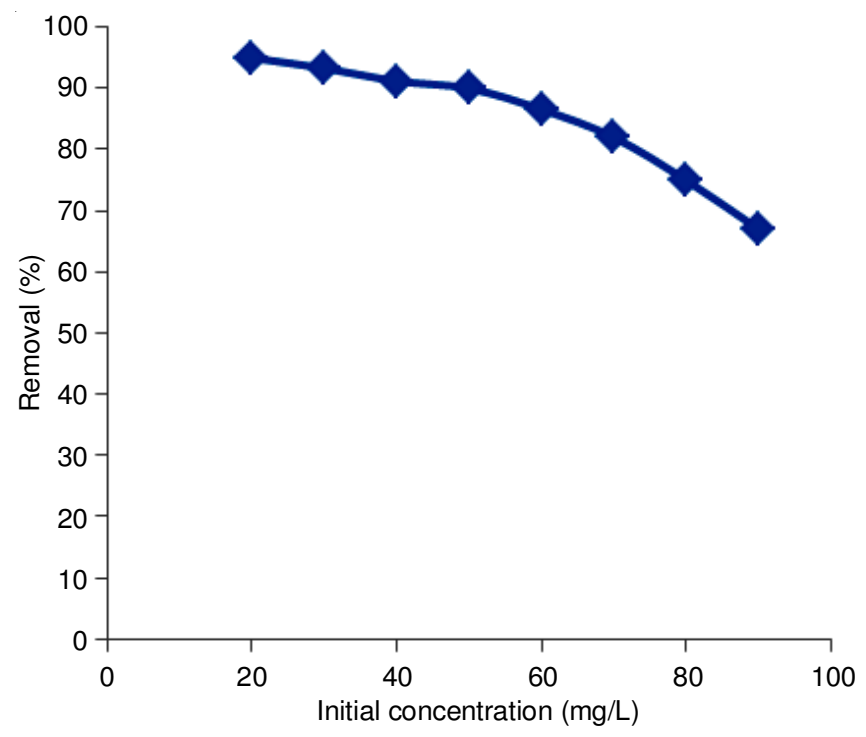

Fig. 7(e). Effect of initial concentration on the adsorption

At lower concentrations of phosphate ions, the availability of binding sites of the adsorbent (ZRMAB) are more and hence extraction of phosphate ions is more. With the fixed amount of adsorbent, only a definite amount of adsorption sites are available and hence as the initial concentration of phosphate ion increases, there is a multiple competition to secure the sorption sites and this results in the decrease in the \% removal.

Effect of co-ions: The effect of commonly found co-ions in natural waters on the \% removal of phosphate has been studied by keeping the concentration of the foreign ions by 5 fold excess. The ions studied are $\mathrm{SO}_{4}{ }^{2-}, \mathrm{NO}_{3}{ }^{-}, \mathrm{Cl}^{-}, \mathrm{F}^{-}$and $\mathrm{HCO}_{3}{ }^{-}$. The results are presented in Fig. 7(f). It can be inferred that bicarbonate and fluoride has no effect while chloride and nitrate

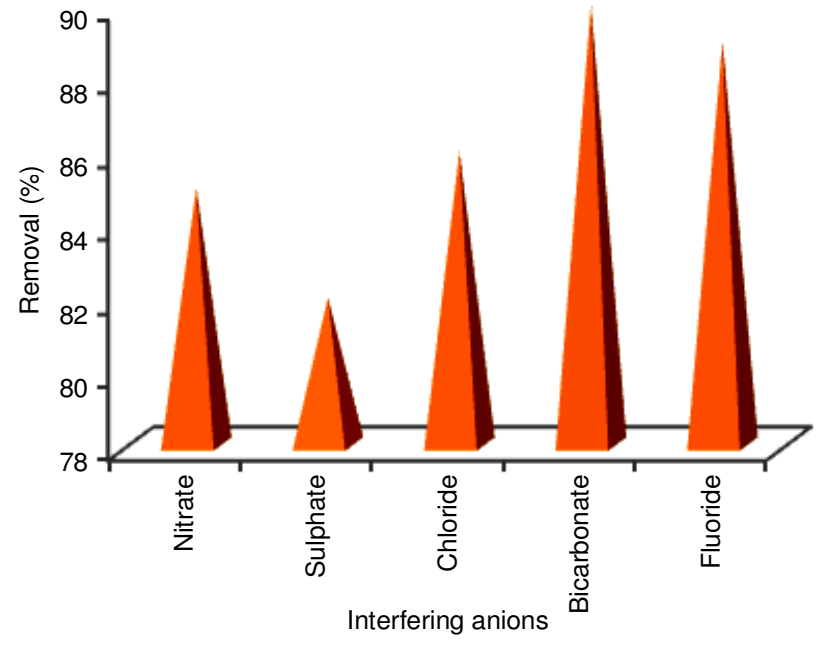

Fig. 7(f). Effect of interfering anions on the adsorption 
has marginal effect. Sulphate is found to interfere to some extent and $\%$ of removal has come down from 90 to $82 \%$.

Thermodynamic studies: With increasing the temperature from 303 to $333 \mathrm{~K}$, adsorption of phosphate ions onto the adsorbent (ZRMAB) also increases from 90 to $97 \%$ while maintaining the other conditions of extraction at optimum level namely: $\mathrm{pH}$ : 8, contact time: $120 \mathrm{~min}$, initial concentration of phosphate: $50 \mathrm{mg} / \mathrm{L}, \mathrm{rpm}$ : 250, adsorbent dosage: $1 \mathrm{~g} / 100 \mathrm{~mL}$. This indicates that adsorption of phosphate onto the ZRMAB is favoured at high temperatures and the findings are shown in Fig. 8(a-b).

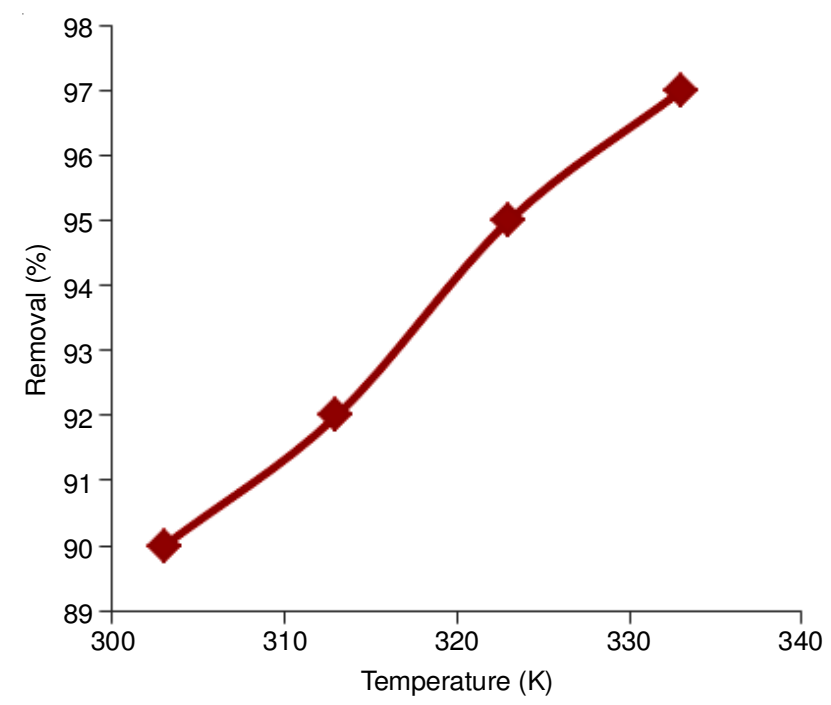

Fig. 8(a). Effect of temperature on adsorption of phosphate

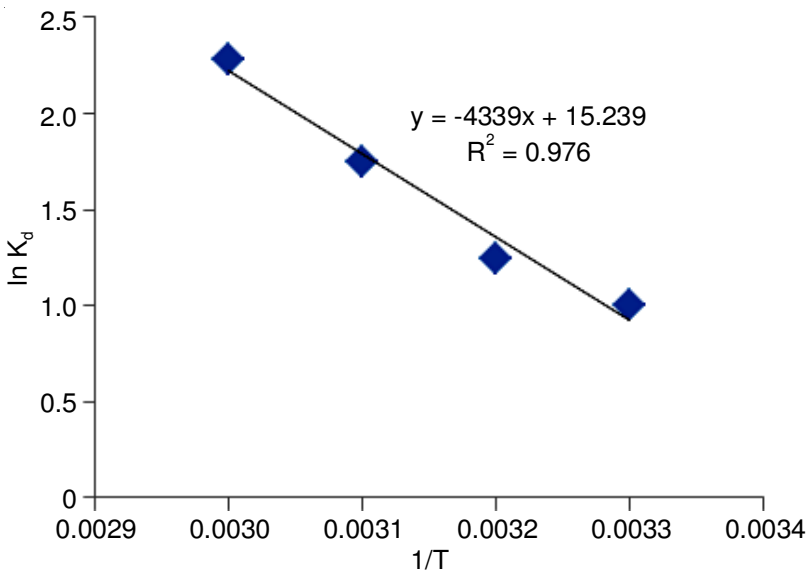

Fig. 8(b). Effect of temperature on adsorption of phosphate

In order to evaluate the adsorption process, energy, enthalpy and entropy considerations are to be taken into account to determine the nature of the adsorption. At different temperatures, free energy change $(\Delta \mathrm{G})(\mathrm{kJ} / \mathrm{mol})$, enthalpy change $(\Delta \mathrm{H})(\mathrm{kJ} /$ $\mathrm{mol})$ and entropy change $(\Delta \mathrm{S})(\mathrm{kJ} / \mathrm{mol})$ are determined by using the eqns. 3 to 5 .

$$
\begin{gathered}
\Delta \mathrm{G}=-\mathrm{RT} \ln \mathrm{K}_{\mathrm{d}} \\
\ln \mathrm{K}_{\mathrm{d}}=\Delta \mathrm{S} / \mathrm{R}-\Delta \mathrm{H} / \mathrm{RT} \\
\mathrm{K}_{\mathrm{d}}=\mathrm{q}_{\mathrm{e}} / \mathrm{C}_{\mathrm{e}} ; \Delta \mathrm{G}=\Delta \mathrm{H}-\mathrm{T} \Delta \mathrm{S}
\end{gathered}
$$

where, $\mathrm{q}_{\mathrm{e}}$ is the adsorbed amount of phosphate onto the adsorbent at equilibrium, $K_{d}$ is the distribution coefficient, $C_{e}$ is the equilibrium concentration of phosphate ion solution, $\mathrm{R}$

\begin{tabular}{|c|c|c|c|c|c|c|}
\hline \multicolumn{7}{|c|}{$\begin{array}{c}\text { TABLE-2 } \\
\text { THERMODYNAMIC PARAMETERS OF ADSORPTION } \\
\text { OF THE PHOSPHATE ON ADSORBENT }\end{array}$} \\
\hline $\begin{array}{c}\Delta \mathrm{H} \\
(\mathrm{kJ} / \mathrm{mol})\end{array}$ & $\begin{array}{c}\Delta \mathrm{S} \\
(\mathrm{J} / \mathrm{mol})\end{array}$ & & $\Delta \mathrm{G}(\mathrm{l}$ & /mol) & & $\mathrm{R}^{2}$ \\
\hline 36.074 & 126.69 & $\begin{array}{c}-2.313 \\
(303 K)\end{array}$ & $\begin{array}{l}-3.579 \\
(313 \mathrm{~K})\end{array}$ & $\begin{array}{l}-4.846 \\
(323 \mathrm{~K})\end{array}$ & $\begin{array}{c}-6.113 \\
(333 \mathrm{~K})\end{array}$ & 0.976 \\
\hline
\end{tabular}
is the gas constant and $\mathrm{T}$ is the absolute temperature in Kelvin and the values obtained are presented in the Table-2 $[42,43]$.

The negative $\Delta G$ values (calculated from the equation $\Delta \mathrm{G}=\Delta \mathrm{H}-\mathrm{T} \Delta \mathrm{S}$ ) indicates that the nature of the adsorption is spontaneous and the positive $\Delta \mathrm{H}$ value (36.074) reflects that the adsorption process is endothermic and physisorption in nature. Further, the positive value of entropy change $(\Delta S)$ reveals the increase in randomness at the solid/solution interface during the adsorption process and good affinity of phosphate ions towards the adsorbent (ZRMAB).

Adsorption isothems: The adsorption isotherms reveal how the adsorbed molecules spread between the solid phase and liquid phase when the sorption process attains an equilibrium stage. Four adsorption isotherm models namely Freundlich [44], Langmuir [45], Temkin [46] and DubininRadushkevich [47], related to sorption equilibrium have been examined in the present investigation. The Freundlich adsorption isotherm model is satisfactory for a low concentrations of adsorbate and at heterogeniuos surface. It is described by eqn. 6 as follows:

$$
\log \left(\mathrm{q}_{\mathrm{e}}\right)=\log \mathrm{k}_{\mathrm{f}}+\left(\frac{1}{\mathrm{n}}\right) \log \mathrm{C}_{\mathrm{e}}
$$

where $\mathrm{C}_{\mathrm{e}}$ is the adsorption capacity $\left(\mathrm{mg} \mathrm{g}^{-1}\right)$ and $\mathrm{n}$ is the empirical parameter. These parameters can be computed from the slope and intercept of the liner plot of $\log \mathrm{C}_{\mathrm{e}} v s$. $\log \mathrm{q}_{\mathrm{e}}$. The linear form of Langmuir isotherm model presumes the homogeneous surface and mono layer adsorption. The equation for Langmuir isotherm model is:

$$
\begin{aligned}
\left(\mathrm{C}_{\mathrm{e}} / \mathrm{q}_{\mathrm{e}}\right) & =\left(\mathrm{a}_{\mathrm{L}} / \mathrm{k}_{\mathrm{L}}\right) \mathrm{C}_{\mathrm{e}}+1 / \mathrm{k}_{\mathrm{L}} \\
\mathrm{R}_{\mathrm{L}} & =1 /\left(1+\mathrm{a}_{\mathrm{L}} \mathrm{C}_{\mathrm{i}}\right)
\end{aligned}
$$

where $\mathrm{q}_{\mathrm{e}}$ is the amount of adsorbed phosphate ions, $\mathrm{k}_{\mathrm{L}}$ and $\mathrm{a}_{\mathrm{L}}$ are the Langmuir constants. The formula (eqn. 8) gives the dimensionless separation factor $\left(R_{L}\right)$ [48]. If $R_{L}=1$, the adsorption is linear; $\mathrm{R}_{\mathrm{L}}>1$, the adsorption process is unfavourable; $\mathrm{R}_{\mathrm{L}}=0$, the adsorption is irreversible and $0<\mathrm{R}_{\mathrm{L}}<1$, the adsorption is favourable. The obtained results and plots while studying these two adsorption isotherms are presented in the Table-3 and Fig. 9(a-b).

For Freundlich model and Langmuir model, $\mathrm{R}^{2}$ values found are: 0.9135 and 0.9987 , respectively. This implies that Langmuir adsorption isotherm model is more acceptable indicating the homogenous nature of the adsorbent and the mono layer formation of phosphate onto the surface of the adsorbent. Furthermore, the $R_{L}$ value: $0.0464\left(0<R_{L}<1\right)$ indicates the favourable nature of the adsorption of phosphate onto the adsorbent (ZRMAB). 


\begin{tabular}{cllccc}
\hline \multicolumn{3}{c}{$\begin{array}{c}\text { TABLE-3 } \\
\text { ADSORPTION PARAMETERS }\end{array}$} \\
\hline S. No. & \multicolumn{1}{c}{ Adsorption isotherms and kinetics } & & Slope & Intercept & $\mathrm{R}^{2}$ \\
\hline 1 & Freundlich isotherm & & 0.3446 & 0.5296 & 0.9135 \\
2 & Langmuir isotherm & $\mathrm{R}_{\mathrm{L}}=0.0464$ & 0.0997 & 0.243 & 0.9987 \\
3 & Temkin isotherm & $\mathrm{B}=1.9981$ & 1.9981 & 3.1489 & 0.9598 \\
4 & Dubinin-Radushkevich isotherm & $\mathrm{E}=1.1180$ & $-4 \mathrm{E}-07$ & 2.0709 & 0.8574 \\
5 & Pseudo-first-order model & & -0.0095 & 0.6043 & 0.9912 \\
6 & Pseudo-second-order model & & 0.1322 & 2.3339 & 0.9930 \\
7 & Elovich model & & 1.2978 & 0.4219 & 0.9692 \\
8 & Bangham's pore diffusion model & & 0.2522 & -1.9179 & 0.9800 \\
\hline
\end{tabular}

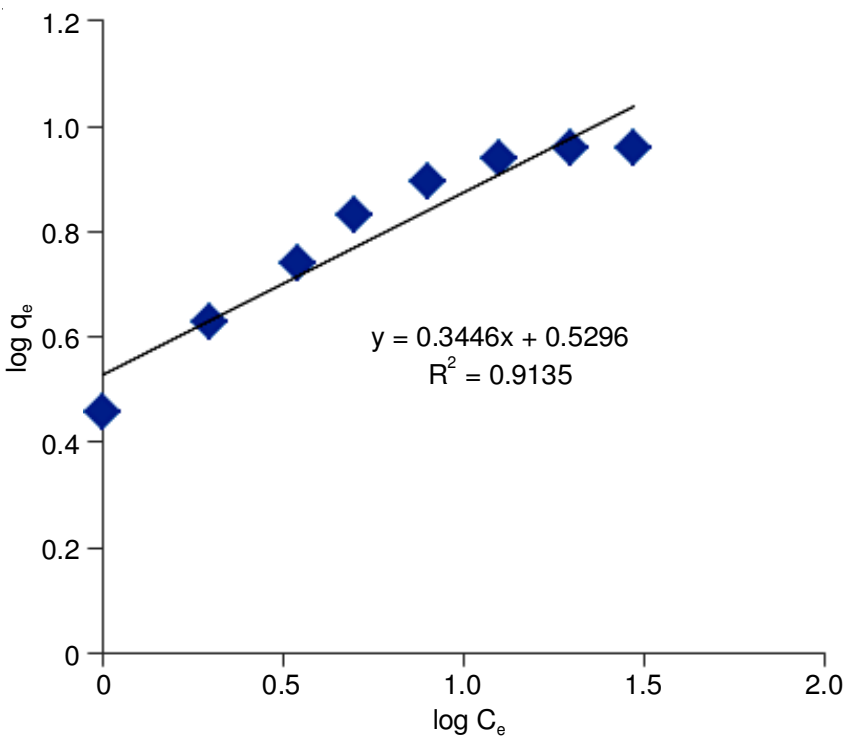

Fig. 9(a). Freundlich adsorption isotherm

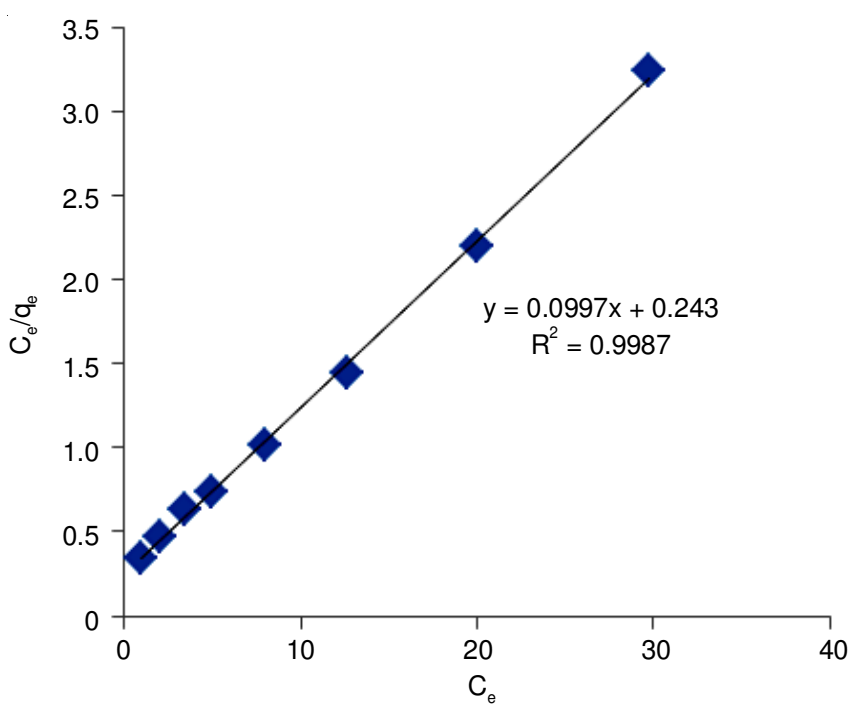

Fig. 9(b). Langmuir adsorption isotherm

Further, Temkin and Dubinin-Radushkevich isotherms are also used in analyzing the sorption process and the results are presented in Fig. 9(c-d). Temkin linear equation used is:

$$
\mathrm{q}_{\mathrm{e}}=\mathrm{B} \ln \mathrm{C}_{\mathrm{e}}+\mathrm{B} \ln \mathrm{A}
$$

where $\mathrm{A}$ and $\mathrm{B}$ are the Temkin isotherm constant $(\mathrm{L} / \mathrm{g})$ and heat of sorption $(\mathrm{J} / \mathrm{mol})$ respectively and $\mathrm{B}$ is calculated from the eqn. 10:

$$
\mathrm{RT} / \mathrm{b}=\mathrm{B}
$$

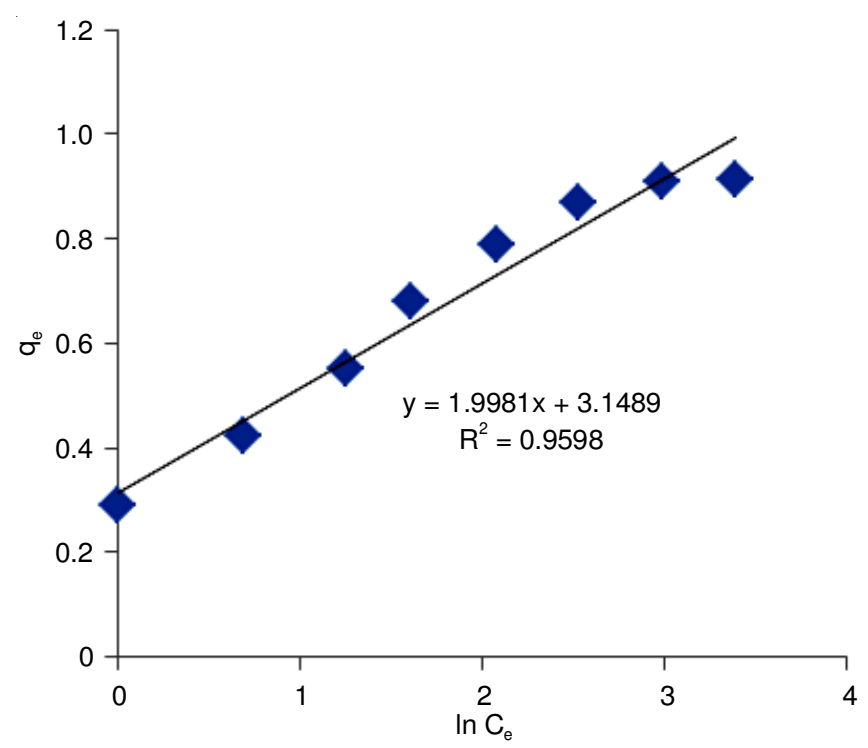

Fig. 9(c). Temkin adsorption isotherm

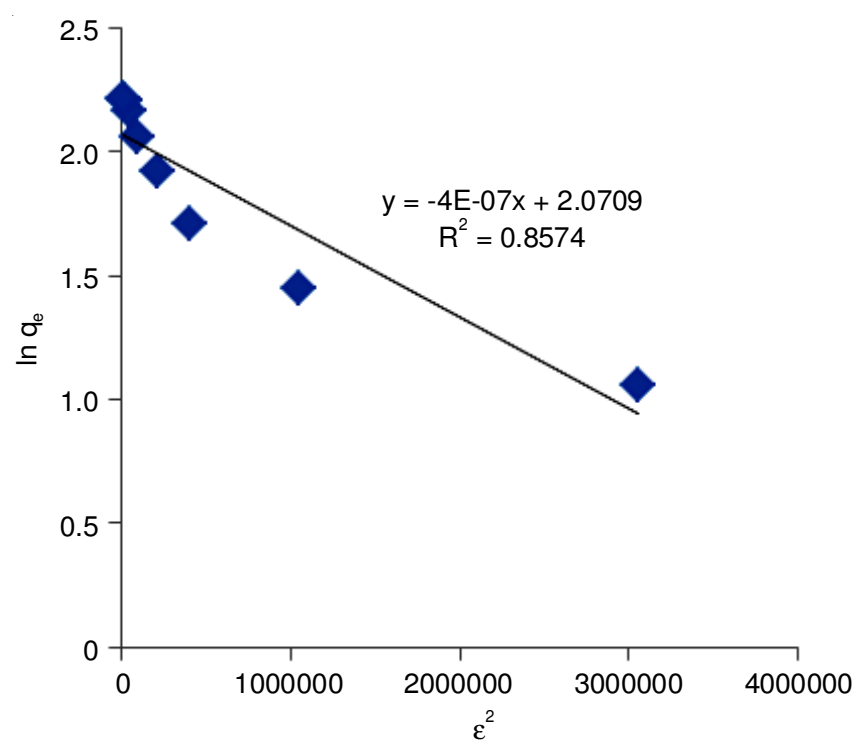

Fig. 9(d). Dubinin- Radushkevich adsorption isotherm

where $\mathrm{b}$ is the Temkin isotherm constant linked to the energy parameter, $\mathrm{R}$ is the gas constant $(\mathrm{J} / \mathrm{mol} / \mathrm{k})$ and $\mathrm{T}$ is the absolute temperature in kelvin. Linear form of Dubinin-Radushkevich equation used is

$$
\ln \mathrm{q}_{\mathrm{e}}=-\beta \varepsilon^{2}+\ln \mathrm{q}_{\mathrm{m}}
$$

where $\varepsilon=\mathrm{RT} \ln \left(1+1 / \mathrm{C}_{\mathrm{e}}\right), \beta$ is a constant related to energy and $\mathrm{q}_{\mathrm{m}}$ is the Dubinin- Radushkevich monolayer adsorption 
capacity $(\mathrm{mol} / \mathrm{g})$. The linear plots of these isotherms are presented in Fig. 9(c-d) and the correlation coefficient and isothermal constants are presented in Table-3. By using the formula $E=1 / \sqrt{ } 2 \beta$ and by slope of Temkin isotherm constants, the mean free energy (E) and heat of sorption (B) are calculated, respectively. As mean free energy (E) is less than $8 \mathrm{~kJ} / \mathrm{mol}$ (i.e., 1.118) and B is less than $20 \mathrm{~kJ} / \mathrm{mol}$ (i.e., 1.998), the mechanism of adsorption is "physisorption" in nature i.e. non-specific adsorption due to long range weak vander Waals forces between adsorbents and adsorbates.

Adsorption kinetics: The kinetics of adsorption are analyzed using four well known models namely pseudo-first order [49], pseudo-second order [50], Bangham's pore diffusion [51] and Elovich model [52] using eqns. 12 to 15 as follows:

Pseudo-first order:

$$
\log \left(\mathrm{q}_{\mathrm{e}}-\mathrm{q}_{\mathrm{t}}\right)=\log \mathrm{q}_{\mathrm{e}}-\frac{\mathrm{K}_{1}}{2.303} \mathrm{t}
$$

\section{Pseudo-second order:}

$$
\frac{\mathrm{t}}{\mathrm{q}_{\mathrm{t}}}=\frac{1}{\mathrm{~K}_{2} \mathrm{q}_{\mathrm{e}}^{2}}+\frac{1}{\mathrm{q}_{\mathrm{e}}} \mathrm{t}
$$

\section{Bangam's pore diffusion model:}

$$
\log \left[\log \left(\frac{\mathrm{C}_{\mathrm{i}}}{\mathrm{C}_{\mathrm{i}}-\mathrm{q}_{\mathrm{t}} \mathrm{m}}\right)\right]=\log \left(\frac{\mathrm{K}_{\mathrm{o}}}{2.303 \mathrm{~V}}\right)+\propto \log (\mathrm{t})
$$

\section{Elovich equation:}

$$
\mathrm{q}_{\mathrm{t}}=\frac{1}{\beta} \ln (\propto \beta)+\frac{1}{\beta} \ln (\mathrm{t})
$$

The results are presented in Fig. 10(a-d) and Table-3. The correlation coefficient value $\left(\mathrm{R}^{2}\right)$ are found in the order: pseudo-second-order $(0.9930)>$ pseudo-first-order (0.9912) $>$ Bangham's pore diffusion model $(0.9800)>$ Elovich model (0.9692). Hence, pseudo second-order model describe well the kinetics of adsorption.

Applications: The methodology developed in this work is applied to real polluted lake water samples collected in the Bapatla Mandalam of Guntur District of Andhra Pradesh (India)

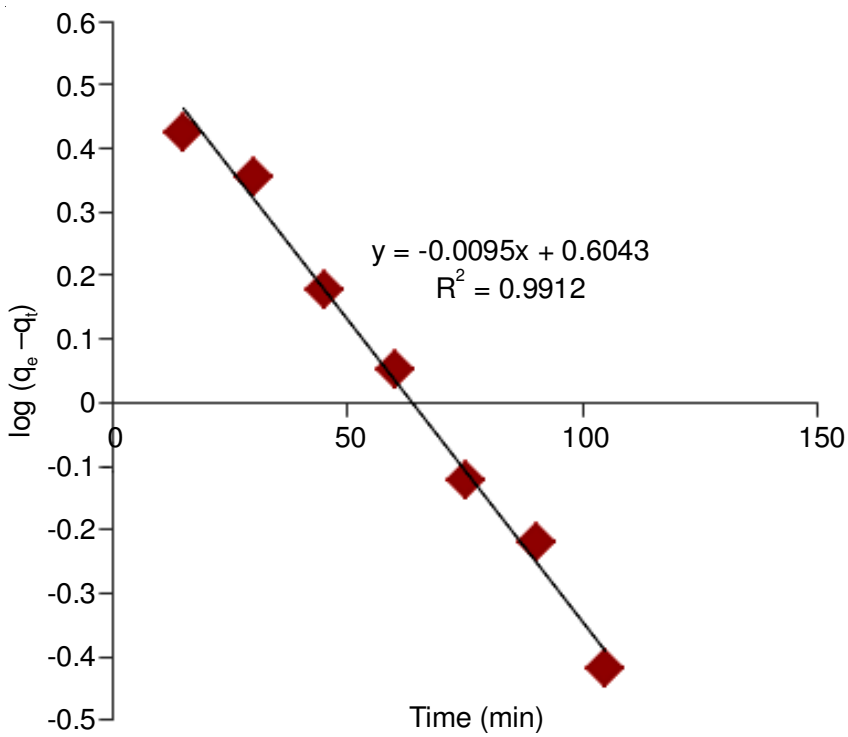

Fig. 10(a). Pseudo-first order kinetics

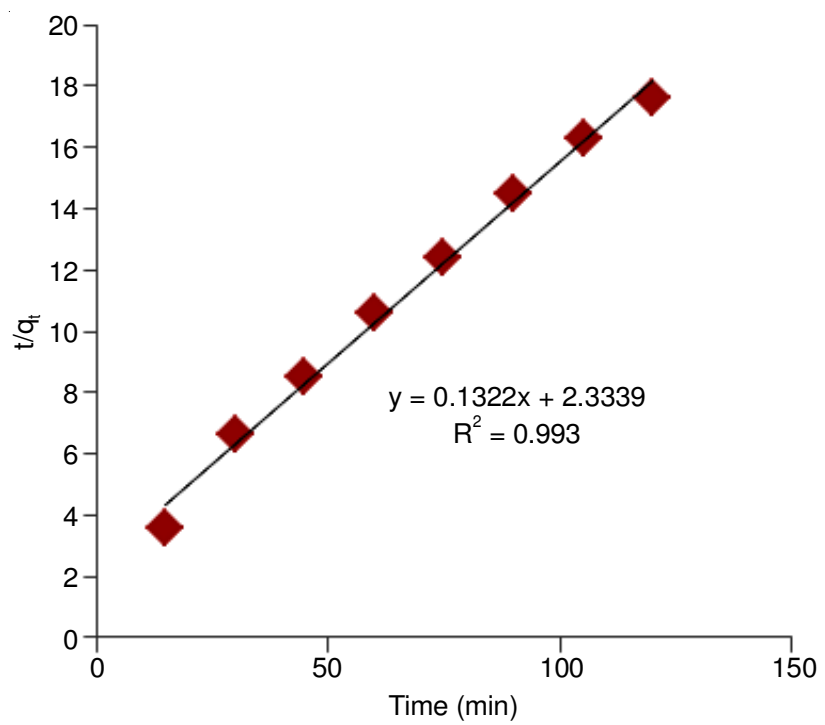

Fig. 10(b). Pseudo-second order kinetics

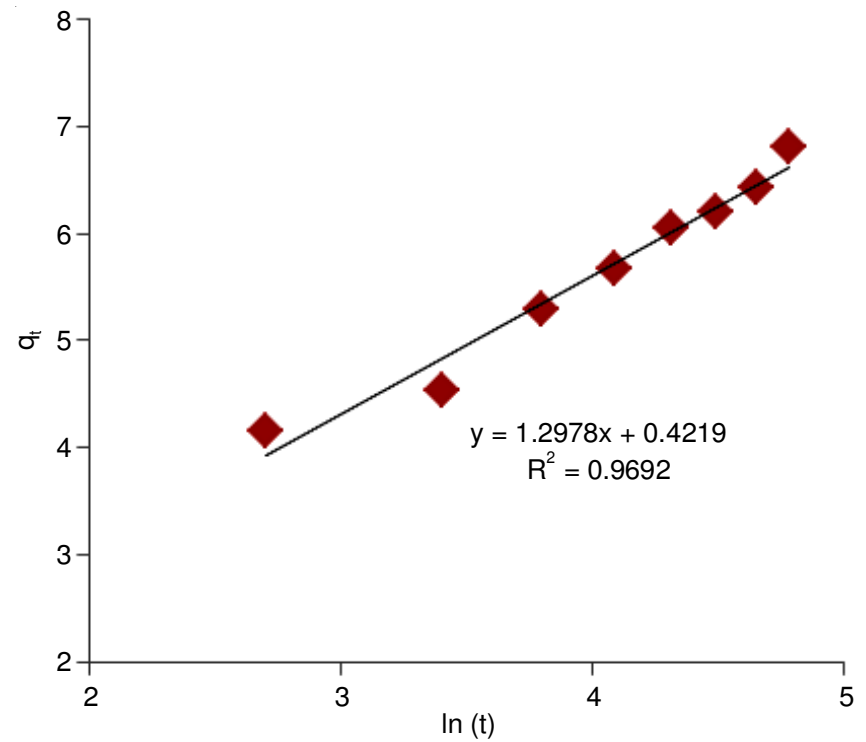

Fig. 10(c). Elovich model

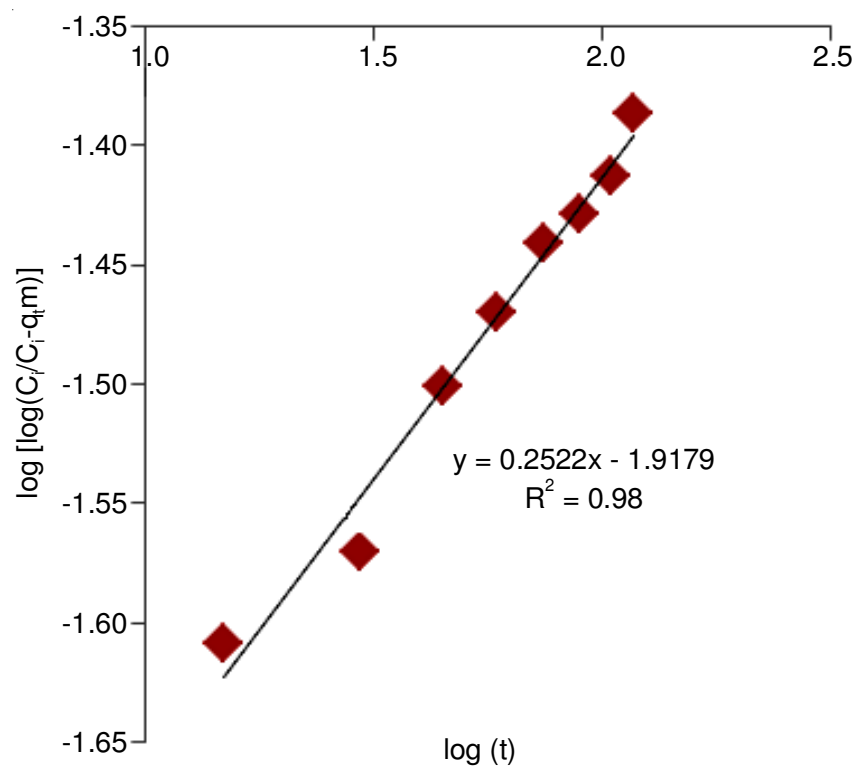

Fig. 10(d). Bangam pore diffusion model 
where the phosphate contamination of lake waters is more due to excess utilization of fertilizers in the vast stretches of agricultural fields. The observations noted are presented in Table-4. It is seen from the Table-4 that the adsorbent and procedure developed in this work is successful in removing the phosphate not less than nearly $80 \%$.

\begin{tabular}{|c|c|c|c|}
\hline \multicolumn{4}{|c|}{$\begin{array}{c}\text { TABLE-4 } \\
\text { PHOSPHATE CONCENTRATION (BEFORE AND AFTER) } \\
\text { OF POLLUTED WATER SAMPLES AT DIFFERENT } \\
\text { PLACES IN ANDHRA PRADESH, INDIA }\end{array}$} \\
\hline $\begin{array}{c}\text { Water } \\
\text { samples }\end{array}$ & $\begin{array}{l}\mathrm{C}_{\mathrm{i}}(\mathrm{mg} / \mathrm{L}) \text { (initial } \\
\text { concentration of } \\
\text { Phosphate ions) }\end{array}$ & $\begin{array}{l}\mathrm{C}_{\mathrm{f}}(\mathrm{mg} / \mathrm{L}) \text { (final } \\
\text { concentration of } \\
\text { Phosphate ions) }\end{array}$ & $\begin{array}{c}\text { Removal } \\
(\%)\end{array}$ \\
\hline Sample 1 & 13.5 & 1.74 & 87.1 \\
\hline Sample 2 & 17.7 & 2.40 & 86.4 \\
\hline Sample 3 & 20.3 & 3.34 & 83.5 \\
\hline Sample 4 & 25.8 & 4.46 & 82.7 \\
\hline Sample 5 & 29.2 & 5.89 & 79.8 \\
\hline
\end{tabular}

Comparison: The phosphate sorption ability of ZRMAB is compared with the various adsorbents reported hitherto in the literature and comparison is presented in Table-5. It may be inferred that the present developed adsorbent has good adsorption ability than many adsorbents developed so far and further, the immobilization of the zirconium activated red mud in zinc-alginate beads, renders the filtration easy.

Regeneration and reuse: The reusability of adsorbent (ZRMAB) is studied by treating the adsorbent with different solutions namely acids, base and salt solution. With $0.1 \mathrm{M} \mathrm{NaOH}$, the bead structure is completely lost with formation of gel and with $0.1 \mathrm{M} \mathrm{Na}_{2} \mathrm{SO}_{4}$ solution, the beads are bulged more weakening the cross links of the beads and furthermore the trapped activated red mud in the beads is coming out. But $0.1 \mathrm{M} \mathrm{HCl}$ is found to be good eluent for regeneration studies.

The effect of number of regenerations on the \% removal of phosphate is studied using $0.1 \mathrm{~N} \mathrm{HCl}$ and the results are shown in Fig. 11. It is seen that even after 10 regenerations, \% removal has not come down below $84.0 \%$ indicating the successful achievement of the developed bead-based adsorbent (ZRMAB) in the removal of phosphates. Hence, by repetitive use of the same adsorbent, it is found to remove phosphate completely from the waters.

\section{Conclusion}

An adsorbent is prepared by impregnating zirconium oxychloride treated fine red mud into the zinc-alginate beads (ZRMAB). Thus developed adsorbent has been probed for its sorption nature towards phosphate ions from water by varying the various physico-chemical parameters such as $\mathrm{pH}$, time of

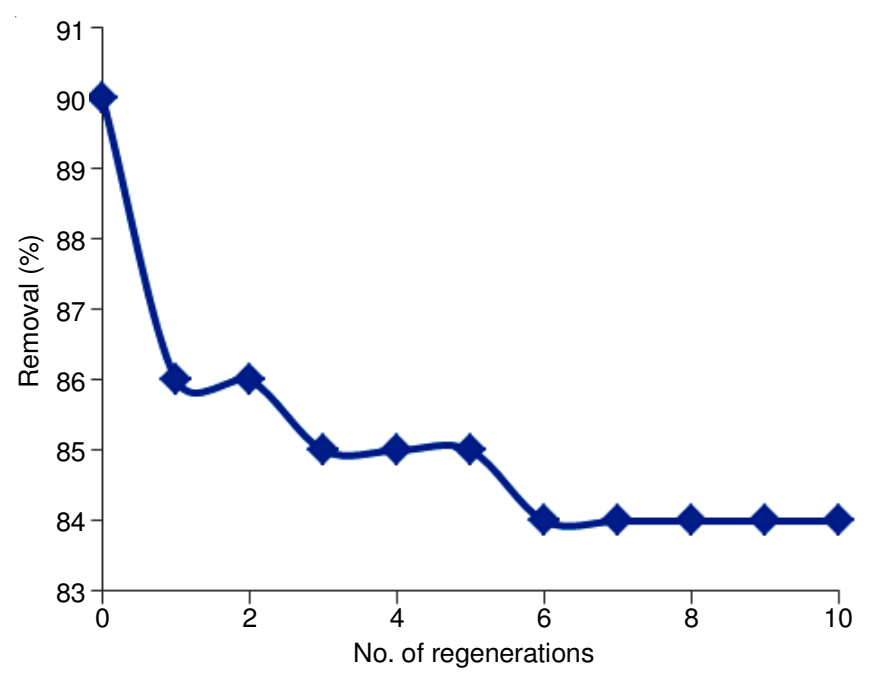

Fig. 11. No. of regenerations vs. removal (\%)

equilibration, sorbent dosage, initial concentration of phosphate, presence of co-anions and temperature and the conditions have been optimized for the maximum extraction of phosphate. It is found that $90 \%$ removal of phosphate is observed at $\mathrm{pH}: 8$, sorbent dosage: $0.33 \mathrm{~g}$ (of doped red mud in $1 \mathrm{~g}$ of ZRMAB beads) $/ 100 \mathrm{~mL}, 120 \mathrm{~min}$ of time of equilibration, $250 \mathrm{rpm}$ and at $30 \pm 1{ }^{\circ} \mathrm{C}$. The commonly found co-anions even in five fold excess have marginally interfered. By immobilizing the activated red mud in the beads, the filtration process is made easy.

The surface morphological studies are made using XRD, FTIR, FESEM and EDX revealed that the phosphate is onto the surface of adsorbent. Thermodynamic parameters have been evaluated and found that the adsorption is spontaneous and "physisorption" in nature. The nature of adsorption is analyzed using Freundlich, Langmuir, Temkin and Dubinin-Radushkevich models and found that the adsorption is well described by Langamuir indicating homogenous surface of the adsorbent and mono-layer formation of the adsorbate (phosphate) on the surface of the adsorbent. The kinetics of adsorption is analyzed using various models and found that the adsorption is well described by pseudo-second-order with $\mathrm{R}^{2}=0.9930$.

$0.1 \mathrm{M} \mathrm{HCl}$ is found to be good eluent for regeneration of the adsorbent and found that even after 10 cycles of regeneration and subsequent use, the adsorbent is effectively removing substantial amounts of phosphate (to an extent of $84 \%$ ). Hence, by repetitive use of the same adsorbent, it is possible to remove phosphate completely from the waters. The method developed using ZRMAB as adsorbent is found to be remarkably successful when applied to polluted lake waters.

TABLE-5

COMPARISON OF MAXIMUM ADSORPTION CAPACITY OF ADSORBENT WITH OTHER ADSORBENTS FROM LITERATURE

\begin{tabular}{|c|c|c|c|c|}
\hline S. No. & Adsorbent & $\mathrm{pH}$ & $\mathrm{q}_{\mathrm{e}}(\mathrm{mg} / \mathrm{g})$ & Reference \\
\hline 1 & $\mathrm{HCl}$ treated red mud & 5.5 & 0.58 & [53] \\
\hline 2 & $\mathrm{ZnCl}_{2}$ activated carbon & 4.0 & 4.2 & [54] \\
\hline 3 & Lanthanum hydroxide- doped activated carbon & 7.0 & 15.3 & [55] \\
\hline 4 & Al pillared bentonite & 3.0 & 5.05 & [56] \\
\hline 5 & Iron hydroxide-eggshell waste & 6.7 & 14.4 & [57] \\
\hline 6 & Industrial solid waste, $\mathrm{Fe}(\mathrm{III}) / \mathrm{Cr}(\mathrm{III})$ hydroxide & 4.0 & 6.5 & [58] \\
\hline 7 & ZRMAB & 8.0 & 13.636 & Present work \\
\hline
\end{tabular}




\section{ACKNOWLEDGEMENTS}

The authors thank the Ministry of Environment \& Forests (MOEF), New Delhi, for granting the project entitled "Red mud as an adsorbent for the removal of pollutants" and under whose financial aid this work has been carried out.

\section{REFERENCES}

1. O.S. Devi and K. Ravindhranath, Indian J. Environ. Prot., 32, 943 (2012).

2. A.N. Babu, G.V.K. Mohan and K Ravindhranath, Int. J. Chemtech Res. 9, 506 (2016).

3. Y. Hanumantha Rao and K. Ravindhranath, Der Pharma Chemica, 7, 286 (2015).

4. K.P.C. Sekhar, R.V. Vishnu Babu, D. Srividhya and K. Ravindhranath, Der Pharma Chemica, 4, 664 (2012).

5. K. Papodu, Y. Hanumantha Rao and K. Ravindhranath, Der Pharma Chemica, 6, 19 (2014).

6. A.A. Kumari and K. Ravindhranath, J. Chem. Pharm. Res., 4, 2836 (2012).

7. A.A. Kumari and K. Ravindhranath, Asian J. Res. Chem, 5, 882 (2012)

8. A.A. Kumari and K. Ravindhranath, Int. J. Chemtech Res., 4, 1733 (2012).

9. A.A. Kumari and K. Ravindhranath, Int. J. Water Resources Environ. Sci., 1, 08 (2012).

10. M. Suneetha, B.S. Sundar and K. Ravindhranath, Int. J. Chemtech Res., 07, 93 (2015).

11. M. Suneetha, B.S. Sundar and K. Ravindhranath, Asian J. Water Environ. Pollut., 12, 33 (2015); https://doi.org/10.3233/AJW-150005.

12. M. Suneetha, B.S. Sundar and K. Ravindhranath, Int. J. Environ. Technol. Manag., 18, 420 (2015); https://doi.org/10.1504/IJETM.2015.073079.

13. Y. Hanumantharao, M. Kishore and K. Ravindhranath, Int. J. Chemtech Res., 4, 1686 (2012).

14. Y. Hanumantharao, M. Kishore and K. Ravindhranath, E.-J. Environ. Agric. Food Chem., 11, 442 (2012).

15. S. Ravulapalli and R. Kunta, J. Fluor. Chem., 193, 58 (2017); https://doi.org/10.1016/j.jfluchem.2016.11.013

16. M. Suneetha and K. Ravindhranath, J. Chem. Pharm. Res., 6, 408 (2014).

17. M. Suneetha and K. Ravindhranath, Int. J. Chem. Environ. Pharm. Res., 3, 24 (2012).

18. K.P. Rani and K. Ravindhranath, Der Pharma Chemica, 6, 56 (2014).

19. M. Suneetha and K. Ravindhranath, Der Pharma Chemica, 4, 214 (2012).

20. K.P. Rani and K. Ravindhranath, J. Chem. Pharm. Res., 6, 889 (2014).

21. Y.H. Rao and K. Ravindhranath, Int. J. Chemtech Res., 8, 784 (2015).

22. M.D. Jyothi, K.R. Kiran and K. Ravindhranath, Int. J. Appl. Environ. Sci., 7, 127 (2012).

23. B.S. Reddy and K. Ravindhranath, Int. J. Chemtech Res., 6, 5612 (2014).

24. B.S. Reddy, B.K. Veni and K. Ravindhranath, J. Chem. Pharm. Res., 4 4682 (2012).

25. B.S. Reddy and K. Ravindhranath, Der Pharm. Lett., 7, 159 (2015).

26. S. Zhang, C. Liu, Z. Luan, X. Peng, H. Ren and J. Wang, J. Hazard. Mater. 152, 486 (2008); https://doi.org/10.1016/j.jhazmat.2007.07.031.

27. V.K. Gupta, M. Gupta and S. Sharma, Water Res., 35, 1125 (2001); https://doi.org/10.1016/S0043-1354(00)00389-4.

28. M. Ma, Y. Lu, R. Chen, L. Ma and Y. Wang, Open J. Appl. Sci. (Faisalabad), 4, 275 (2014);

https://doi.org/10.4236/ojapps.2014.45027.

29. H. Nadaroglu and E. Kalkan, Int. J. Phys. Sci., 7, 1386 (2012).

30. R.C. Sahu, R. Patel and B.C. Ray, Desalination, 266, 93 (2011); https://doi.org/10.1016/j.desal.2010.08.007.
31. A.M. Baraka and M. Marwa, Austr. J. Basic Appl. Sci., 6, 500 (2012).

32. A. Bhatnagar, V.J.P. Vilar, C.M.S. Botelho and R.A.R. Boaventura, Environ. Technol., 32, 231 (2011); https://doi.org/10.1080/09593330.2011.560615.

33. G.V. Krishna Mohan, A. Naga Babu, K. Kalpana and K. Ravindhranath, Der Pharma Chemica, 8, 403 (2016).

34. G.V. Krishna Mohan, A. Naga Babu, K. Kalpana and K. Ravindhranath, Int. J. Chemtech. Res., 9, 1 (2016).

35. G. Newcombe, R. Hayes and M. Drikas, Colloids Surf. A, 78, 65 (1993); https://doi.org/10.1016/0927-7757(93)80311-2.

36. K. Kadirvelu, C. Faur-Brasquet and P.L. Cloirec, Langmuir, 16, 8404 (2000); https://doi.org/10.1021/la0004810.

37. Metcalf and Eddy, Wastewater Engineering: Treatment of Reuse, McGraw Hill Co., New York, edn 4 (2003).

38. G. Kiely, Environmental Engineering. McGraw-Hall International Editions (1998).

39. A.R.K. Trivedy, Pollution Management in Industries, Environmental Publications, Karad, India, edn 2 (1995).

40. APHA (American Public Health Association), Standard Methods for the Examination of Water and Wastewater, APHA, Washington, DC (1985).

41. P.J. Linstrom, NIST Chemistry Webbook, U.S. Department of Commerce (2009).

42. G. Karthikeyan and S.S. Elango, Iran. J. Environ. Health Sci. Eng., 4, 21 (2007).

43. G. Alagumuthu and M. Rajan, Chem. Eng. J., 158, 451 (2010); https://doi.org/10.1016/j.cej.2010.01.017.

44. H.M.F. Freundlich, Z. Phys. Chem., 57, 385 (1907); https://doi.org/10.1515/zpch-1907-5723.

45. I. Langmuir, J. Am. Chem. Soc., 40, 1361 (1918); https://doi.org/10.1021/ja02242a004.

46. M.J. Temkin and V. Pyzhev, Acta Physiochim. URSS, 12, 217 (1940).

47. M.M. Dubinin and L.V. Radushkevich, Proc. Acad. Sci. Phys. Chem., 55, 331 (1947).

48. K.R. Hall, L.C. Eagleton, A. Acrivos and T. Vermeulen, Ind. Eng. Chem. Fundam., 5, 212 (1966); https://doi.org/10.1021/i160018a011.

49. J.F. Corbett, J. Chem. Educ., 49, 663 (1972); https://doi.org/10.1021/ed049p663.

50. Y.S. Ho and G. McKay, Process Biochem., 34, 451 (1999); https://doi.org/10.1016/S0032-9592(98)00112-5.

51. Y.S. Ho, J.C.Y. Ng and G. McKay, Sep. Purif. Methods, 29, 189 (2000); https://doi.org/10.1081/SPM-100100009.

52. S. Lagergren, K. Sven. Vetensk. Akad. Handl., 24, 1 (1898).

53. W. Huang, S. Wang, Z. Zhu, L. Li, X. Yao, V. Rudolph and F. Haghseresht, J. Hazard. Mater, 158, 35 (2008); https://doi.org/10.1016/j.jhazmat.2008.01.061.

54. C. Namasivayam and D. Sangeetha, J. Colloid Interface Sci., 280, 359 (2004); https://doi.org/10.1016/j.jcis.2004.08.015.

55. L. Zhang, Q. Zhou, J. Liu, N. Chang, L. Wan and J. Chen, Chem. Eng. J., 185-186, 160 (2012); https://doi.org/10.1016/j.cej.2012.01.066.

56. L.G. Yan, Y.Y. Xu, H.Q. Yu, X.D. Xin, Q. Wei and B. Du, J. Hazard. Mater, 179, 244 (2010); https://doi.org/10.1016/j.jhazmat.2010.02.086.

57. N.Y. Mezenner and A. Bensmaili, Chem. Eng. J., 147, 87 (2009); https://doi.org/10.1016/j.cej.2008.06.024.

58. C. Namasivayam and K. Prathap, J. Hazard. Mater., 123, 127 (2005); https://doi.org/10.1016/j.jhazmat.2005.03.037. 